\title{
Impact of Ovarian Metastatectomy on Survival Outcome of Colorectal Cancer Patients with Ovarian Metastasis: A Retrospective Study
}

This article was published in the following Dove Press journal: Cancer Management and Research

\section{Xiaofen Li (D) \\ Hai Huang ${ }^{1,2}$ \\ Longyao $\operatorname{Ran}^{3}$ \\ Chao Fang ${ }^{4}$ \\ Yongyang $\mathrm{Yu}^{4}$ \\ Manxi Luo ${ }^{5}$ \\ Meng Qiu (D)}

'Department of Abdominal Oncology, West China Hospital of Medicine, Sichuan University, Chengdu, Sichuan, People's Republic of China; ${ }^{2}$ Department of Oncology, People's Hospital of Deyang City, Deyang, Sichuan, People's Republic of China; ${ }^{3}$ Department of Medical Administration, West China Hospital of Medicine, Sichuan University, Chengdu, Sichuan, People's Republic of China; ${ }^{4}$ Department of Gastrointestinal Surgery, West China Hospital of Medicine, Sichuan University, Chengdu, Sichuan, People's Republic of China; ${ }^{5}$ Faculty of Medicine, The University of New South Wales, Kensington, New South Wales, Australia
Background: Ovarian metastasis from colorectal cancer (CRC) is rare and lacks standard treatment. The benefit of metastatectomy remains to be elucidated. This study was conducted to assess the impact of metastatectomy on survival outcome and explore prognostic factors in ovarian metastatic CRC patients.

Methods: Information of ovarian metastatic CRC patients between January 2008 and December 2017 were collected retrospectively from database of West China Hospital, Sichuan University. Kaplan-Meier method was used to estimate disease-specific survival (DSS) after diagnosis of ovarian metastasis, and multivariate Cox regression analysis was applied to identify prognostic factors.

Results: Totally, 68 female patients from a cohort of 2170 cases were eligible. The median age at diagnosis was 46.5 years. The median DSS was 25.0 months ( $95 \%$ confidence interval $(\mathrm{CI})$ : 21.0-29.0 months). Kaplan-Meier analysis and Log rank test showed that complete resection of ovarian metastases (median DSS: 33.0 months) could significantly prolong patients' survival time, compared with palliative and no resection (median DSS: 20.0 months and 22.0 months, respectively), regardless of systemic chemotherapy $(P<0.05)$. Multivariate analysis demonstrated regional lymph nodes metastasis of primary tumor (hazard ratio (HR): $3.438,95 \% \mathrm{CI}$ : $1.094-10.810, P=0.035$ ), primary tumor resection (HR: 6.436, 95\% CI: $1.770-23.399, P=0.005$ ), differentiation grade (HR: 0.272, 95\% CI: 0.107-0.693, $P=0.006$ ), complete resection of ovarian metastases (vs palliative resection: HR: $17.091,95 \%$ CI: $3.040-96.099, P=0.001$; vs no resection: HR: $9.519,95 \% \mathrm{CI}: 1.581-57.320, P=0.014$ ), and systemic chemotherapy (HR: $3.059,95 \%$ CI: $1.089-8.595 P=0.034)$ were independent prognostic factors.

Conclusion: Complete resection of ovarian metastases could independently predict favorable survival in ovarian metastatic $\mathrm{CRC}$, while palliative resection could not improve patients' prognosis compared with no resection.

Keywords: ovarian metastasis, colorectal cancer, metastatectomy

\section{Plain Language Summary}

There is no standard treatment for ovarian metastatic CRC, which happens rarely and has poor prognosis. To date, the role of surgery for ovarian metastases still remains unclear. We conducted this retrospective study to evaluate the benefit of metastatectomy and explore prognostic factors. In total, 68 patients newly diagnosed with ovarian metastatic CRC were identified from a cohort of 2170 female cases with metastatic CRC. Results showed that the median disease-specific survival was 25.0 months (95\% CI: 21.0-29.0 months). Compared with palliative and no resection of ovarian metastases, complete resection could significantly prolong patients' survival time, regardless of systemic chemotherapy $(P<0.05)$. Multivariate
Department of Abdominal Oncology,

West China Hospital of Medicine, Sichuan

University, No. 37 Guo Xue Xiang,

Chengdu, Sichuan 61004I, People's

Republic of China

Tel + 86-28-85422589

$\mathrm{Fax}+86-28-85423609$

Email qiumeng33@hotmail.com 
analysis identified regional lymph nodes metastasis of primary tumor, primary tumor resection, differentiation grade, complete resection of ovarian metastases, and systemic chemotherapy as independent prognostic factors. Our study indicated that limited ovarian metastases could be the candidates for surgery, which could help clinicians in making individualized treatment strategies.

\section{Introduction}

Ovarian metastasis is relatively rare in colorectal cancer (CRC) female patients, with an incidence of about $0.8-7.4 \%{ }^{1}$ Metastatic ovarian tumors from CRC commonly manifest as cyst-solidary masses on imaging examination, which are indistinguishable from primary ovarian cancer. $^{2}$ It is reported that about $4 \%-29 \%$ CRC patients with ovarian metastases are initially misdiagnosed and receive surgery as primary ovarian malignancies. ${ }^{3-5}$ Pathological diagnosis of CRC ovarian metastasis generally needs assistance of immunohistochemistry, which is characterized as cytokeratin 7 (CK7) -/CK20+/caudal-type homeobox transcription factor-2 (CDX2) +/carbohydrate antigen 125 (CA125) -/paired box gene 8 (PAX8)-. 1,6,7

In recent years, despite rapid progress in treatment strategies of advanced CRC, ovarian metastasis from CRC has poor prognosis. Studies have demonstrated primary resistance of ovarian metastases to systemic chemotherapy, with an objective response rate (ORR) less than 20\%, which is much worse than that of metastases in other organs. ${ }^{8,9}$ Although some retrospective studies with small sizes have indicated survival benefit of ovarian metastasectomy, the role of surgery for ovarian metastases still remains unclear. ${ }^{10}$ The poor prognosis of ovarian metastasis may contribute to easy misdiagnosis and lack of standard treatment. In this study, we summarized clinicopathological characteristics, survival outcome and prognostic factors of ovarian metastatic CRC patients in a single institution during a 10 -year period.

\section{Patients and Methods}

\section{Patient Selection}

Female patients who were newly diagnosed with ovarian metastatic CRC between January 2008 and December 2017 were identified retrospectively from the database of Cancer Center at West China Hospital, Sichuan University. Patients' information and treatment history were obtained through medical records. All patients were followed-up to July 31, 2018.

Data of the patients were collected including age at the time of diagnosis with ovarian metastasis, menopausal status, pretreatment serum carcinoembryonic antigen (CEA) level, primary tumor location, initial $\mathrm{T}$ and $\mathrm{N}$ stage of primary tumor, time interval between diagnosis of primary tumor and that of ovarian metastasis (metachronous vs synchronous), size of ovarian metastases, combined metastases outside ovaries, ascites, surgical methods of ovarian metastases (no resection vs palliative resection vs complete resection), systemic chemotherapy and response evaluation. For patients received surgical resection of ovarian masses, pathological diagnoses were confirmed by immunohistochemistry staining of ovarian specimens (CK7-/CK20+/CDX2+/CA125-/PAX8-). In the current study, the time interval between diagnosis of primary tumor and that of ovarian metastasis exceeding 3 months was defined as metachronous ovarian metastasis, otherwise as synchronous metastasis. Palliative resection of ovarian metastases meant microscopic or macroscopic residual disease in ovaries ( $\mathrm{R} 1$ or $\mathrm{R} 2$ resection), while complete resection referred to no residual disease left in ovaries (R0 resection).

This study was approved by the West China Hospital, Sichuan University Ethic Committee for Clinical Investigation. And all methods were performed in accordance with the relevant guidelines and regulations.

\section{Statistical Analysis}

Median disease-specific survival (DSS) was estimated with Kaplan-Meier method, which was calculated from the date of diagnosis with ovarian metastasis to death (caused by cancer) or last follow-up time. Death caused by CRC was considered as endpoint event. Patients who were still alive at last follow-up time or who had died of other causes were censored. Log rank test was used to compare survival time of different groups and a multivariate Cox proportional hazard regression model was established to determine the associations between survival time and other factors such as age, menopausal status, primary tumor location, ascites, surgical methods of metastases and systemic chemotherapy et al. Statistical tests were two sided and $P<0.05$ was considered statistically significant. SPSS Statistics 22.0 (IBM, Armonk, NY, USA) was applied to perform all the statistical analyses.

\section{Results}

\section{Patient Characteristics}

Patients' clinical characteristics are summarized in Table 1. In total, 68 patients newly diagnosed with ovarian metastatic CRC were identified from a cohort of 2170 female patients with metastatic CRC, including $54.4 \%$ premenopausal patients. Hence, the incidence of ovarian metastases in female 
Table I Characteristics and Univariate Disease-Specific Survival Analysis of Patients with Ovarian Metastatic CRC

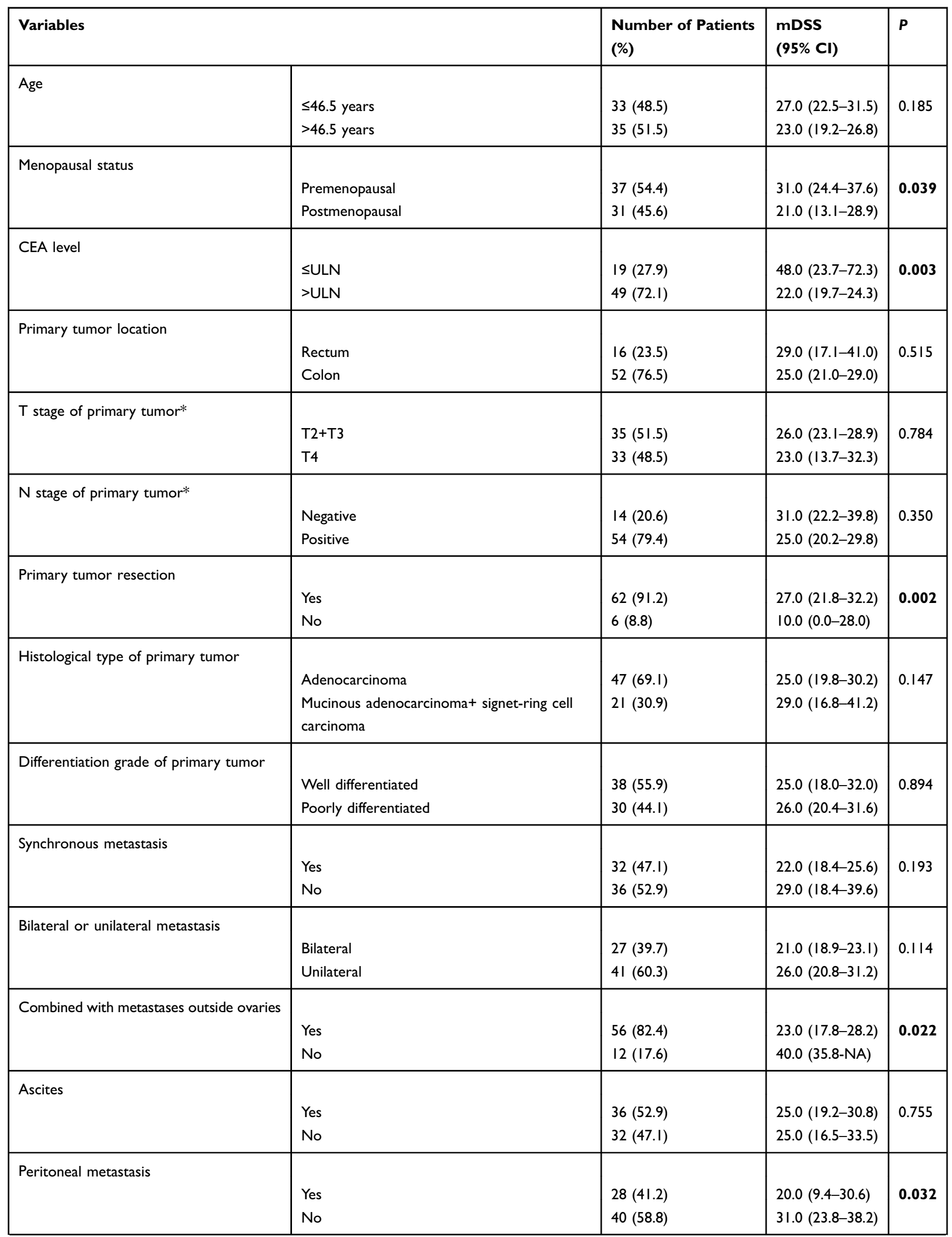


Table I (Continued).

\begin{tabular}{|c|c|c|c|c|}
\hline \multicolumn{2}{|l|}{ Variables } & \multirow{4}{*}{$\begin{array}{l}\begin{array}{l}\text { Number of Patients } \\
\text { (\%) }\end{array} \\
19(27.9) \\
49(72.1)\end{array}$} & \multirow{4}{*}{$\begin{array}{l}\text { mDSS } \\
(95 \% \mathrm{CI}) \\
21.0(12.1-29.9) \\
29.0(21.6-36.4)\end{array}$} & \multirow{4}{*}{$\begin{array}{l}P \\
0.007\end{array}$} \\
\hline Liver metastasis & & & & \\
\hline & Yes & & & \\
\hline & No & & & \\
\hline \multirow[t]{3}{*}{ Lung metastasis } & & & & \\
\hline & Yes & $12(82.4)$ & $23.0(20.0-26.0)$ & 0.158 \\
\hline & No & $56(17.6)$ & $27.0(18.2-35.8)$ & \\
\hline \multirow[t]{3}{*}{ The largest diameter of ovarian metastasis } & & & & \\
\hline & $\leq 8.0 \mathrm{~cm}$ & $36(52.9)$ & $29.0(17.7-40.3)$ & 0.645 \\
\hline & $>8.0 \mathrm{~cm}$ & $32(47.1)$ & $25.0(22.3-27.7)$ & \\
\hline \multirow[t]{4}{*}{ Surgery of ovarian metastasis } & & & & \\
\hline & Complete resection & $29(42.6)$ & $33.0(21.4-44.6)$ & 0.002 \\
\hline & Palliative resection & $28(4 \mid .2)$ & $20.0(13.1-26.9)$ & \\
\hline & No resection (chemotherapy only) & II (16.2) & $22.0(19.5-24.5)$ & \\
\hline \multirow[t]{3}{*}{ Systemic chemotherapy } & & & & \\
\hline & Yes & $48(70.6)$ & $27.0(20.8-33.2)$ & 0.204 \\
\hline & No & $20(29.4)$ & $23.0(9.1-36.9)$ & \\
\hline Total & & $68(100)$ & $25.0(21.0-29.0)$ & - \\
\hline
\end{tabular}

Notes: *In patients without primary tumor resection, the reported $\mathrm{T}$ and $\mathrm{N}$ stage were clinically evaluated based on imaging techniques; Bold text, significant $P$ values $(<0.05)$.

Abbreviations: CRC, colorectal cancer; mDSS, median disease-specific survival; CEA, carcinoembryonic antigen; ULN, upper limit of normal.

metastatic CRC was $3.1 \%$. The median age at diagnosis of ovarian metastasis was 46.5 years. The median time from primary cancer diagnosis to ovarian metastasis detection was 4.5 months. And the median largest diameter of ovarian lesions was $8.0 \mathrm{~cm}$. There were $32(47.1 \%)$ cases presented with synchronous ovarian metastasis, while 36 (52.9\%) with metachronous metastasis. Twelve (17.6\%) patients had metastases confined in the ovaries, whereas the left $56(82.4 \%)$ patients presented with extraovarian metastases in liver, lung, peritoneum, bone, etc. when diagnosed with ovarian metastatic CRC. More than half of the patients $(52.9 \%)$ had ascites and $41.2 \%$ had peritoneal metastasis. As to treatment approach, $42.6 \%$ of all cases underwent complete resection of ovarian metastases, $41.2 \%$ of cases received palliative resection, and the left $16.2 \%$ patients did not undergo ovarian metastatectomy. Most patients $(70.6 \%)$ received systemic chemotherapy after diagnosis of ovarian metastasis. In the group of no resection, all the patients received systemic chemotherapy, while in the groups of complete and palliative resection, 55.2 and $75 \%$ patients received chemotherapy, respectively. Patients refused chemotherapy for a variety of reasons, such as unsatisfactory postoperative recovery, concerning about adverse reactions and cost. All the patients had good performance status when diagnosed with ovarian metastasis, with Eastern Cooperative Oncology Group (ECOG) scores of 0-1.

\section{Survival Analyses for Different Groups}

In total, the median DSS after diagnosed with ovarian metastasis was 25.0 months $(95 \%$ confidence interval (CI) $=21.0-29.0$ months). Univariate survival analysis results are listed in Table 1. In this study, we classified surgical methods of ovarian metastases into three groups, ie, no resection (chemotherapy only), palliative resection (R1 and $\mathrm{R} 2$ resection) and complete resection (R0 resection). Applying Kaplan-Meier method, we found that "complete resection group" showed significantly longer DSS than that of the other two groups ("complete resection group" vs "palliative resection group": 33.0 vs 20.0 months, $P=0.000$; "complete resection group" vs "no resection group": 33.0 vs 22.0 months, $P=0.026$, Figure 1), while median DSS of "palliative resection group" was similar to that of "no resection group" (20.0 vs 22.0 months, $P=0.630$, Figure 1). These results suggested that complete resection of metastatic ovaries predict better survival in CRC patients. 


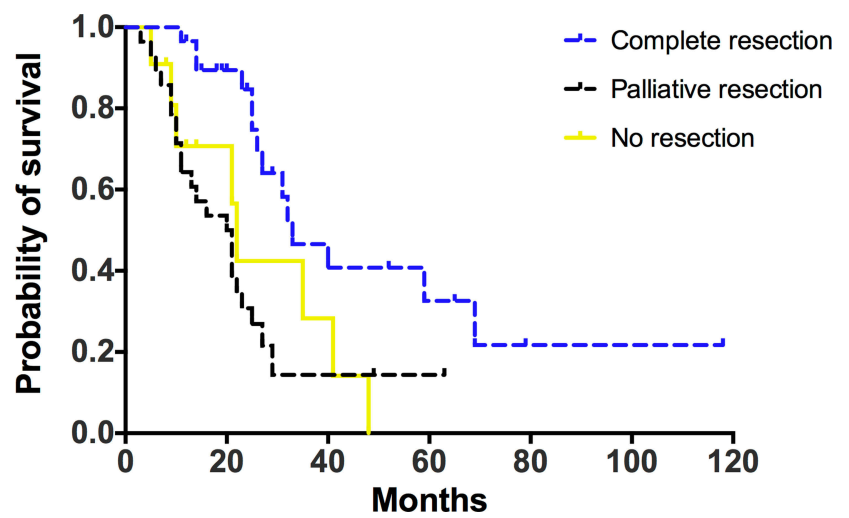

Figure I Disease-specific survival of patients with different surgical methods of ovarian metastases.

Stratified analysis revealed that in patients without systemic chemotherapy, the median DSS of complete resection group was significantly longer than that of palliative resection group ( 26.0 vs 11.0 months, $P=0.001$, Table 2 , Figure 2A). In patients receiving systemic chemotherapy, complete resection also prolonged patients' survival time (vs palliative resection: 69.0 vs 21.0 months, $P=0.002$; vs no resection: 69.0 vs 22.0 months, $P=0.007$ ), while palliative resection could not improve survival outcome compared with no resection (21.0 vs 22.0 months, $P=0.993$, Table 2, Figure 2B).

\section{Prognostic Factors Associated with Survival}

Using multivariate Cox proportional hazard regression analysis, we determined the associations between survival and multiple variables such as age, menopausal status, the levels of CEA, primary tumor location, $\mathrm{T}$ and $\mathrm{N}$ stage of primary tumor, histological type, differentiation grade, primary tumor resection, ascites, synchronous metastasis, bilateral metastasis, size of ovarian metastases, peritoneal metastasis, liver metastasis, lung metastasis, surgical methods of ovarian metastases and systemic chemotherapy. The results demonstrated that regional lymph nodes metastasis of primary tumor (hazard ratio (HR): 3.438, 95\% CI: 1.094-10.810, $P=0.035$ ), primary tumor resection (HR: $6.436,95 \% \mathrm{CI}$ : 1.770-23.399, $P=0.005$ ), differentiation grade (HR: 0.272, 95\% CI: $0.107-0.693, P=0.006$ ), complete resection of ovarian metastases (vs palliative resection: HR: 17.091, 95\% CI: 3.040-96.099, $P=0.001$; vs no resection: HR: 9.519 , 95\% CI: $1.581-57.320, P=0.014$ ), and systemic chemotherapy (HR: 3.059, 95\% CI: $1.089-8.595 P=0.034)$ were independent factors for predicting survival outcome (Table 3 ).

\section{Discussion}

In the current study, we found that in ovarian metastatic $\mathrm{CRC}$, complete resection of ovarian metastases was an independent prognostic factor for favorable survival. Although palliative resection of ovaries could relieve symptoms such as abdominal distension and pain, it failed to improve DSS compared with no resection.

Previous studies have demonstrated ovarian metastases from CRC are resistant to systemic chemotherapy, ${ }^{6,9}$ which is possibly associated with specific gene mutations. ${ }^{11,12}$ Goéré et $\mathrm{al}^{8}$ analyzed chemotherapy response in 23 patients with metastatic (ovarian and extraovarian) CRC, and found that ovarian metastases were less responsive to chemotherapy compared to other sites. The objective response rate (ORR) of ovarian metastases was $0 \%$ and disease control rate (DCR) was $13 \%$, in contrast, ORR and DCR of measurable extraovarian metastases were, respectively, $35 \%$ and $65 \%$. Another study of 33 patients conducted by Lee et $\mathrm{al}^{9}$ also indicated lower ORR of ovarian metastases compared with extraovarian metastases $(18.2 \%$ vs $33.3 \%, P<0.001)$.

Considering resistance to chemotherapy of ovarian metastases, researchers tried to investigate the benefit of

Table 2 Survival Comparison for Patients Receiving Different Methods of Ovarian Metastatectomy Stratified by Chemotherapy

\begin{tabular}{|c|c|c|c|c|c|c|}
\hline \multirow[t]{2}{*}{ Chemotherapy } & \multirow[t]{2}{*}{$\begin{array}{l}\text { Surgery of Ovarian } \\
\text { Metastasis }\end{array}$} & \multirow[t]{2}{*}{$\begin{array}{l}\text { Number of } \\
\text { Patients }\end{array}$} & \multirow[t]{2}{*}{$\begin{array}{l}\text { mDSS } \\
(95 \% \mathrm{CI})\end{array}$} & $\begin{array}{l}\text { Complete } \\
\text { Resection }\end{array}$ & $\begin{array}{l}\text { Palliative } \\
\text { Resection }\end{array}$ & $\begin{array}{l}\text { No } \\
\text { Resection }\end{array}$ \\
\hline & & & & $P$ & $P$ & $\mathbf{P}$ \\
\hline \multirow[t]{2}{*}{ No } & Complete resection & 13 & $26.0(16.9-35.1)$ & - & 0.001 & - \\
\hline & Palliative resection & 7 & II.0 (5.9-I6.I) & 0.001 & - & - \\
\hline \multirow[t]{3}{*}{ Yes } & Complete resection & 16 & $69.0(0.0-140.3)$ & - & 0.002 & 0.007 \\
\hline & Palliative resection & 21 & $21.0(18.0-24.0)$ & 0.002 & & 0.993 \\
\hline & No resection & 11 & $22.0(19.5-24.5)$ & 0.007 & 0.993 & - \\
\hline
\end{tabular}

Note: Bold text, significant $P$ values $(<0.05)$.

Abbreviations: $\mathrm{mDSS}$, median disease-specific survival; $\mathrm{Cl}$, confidence interval. 

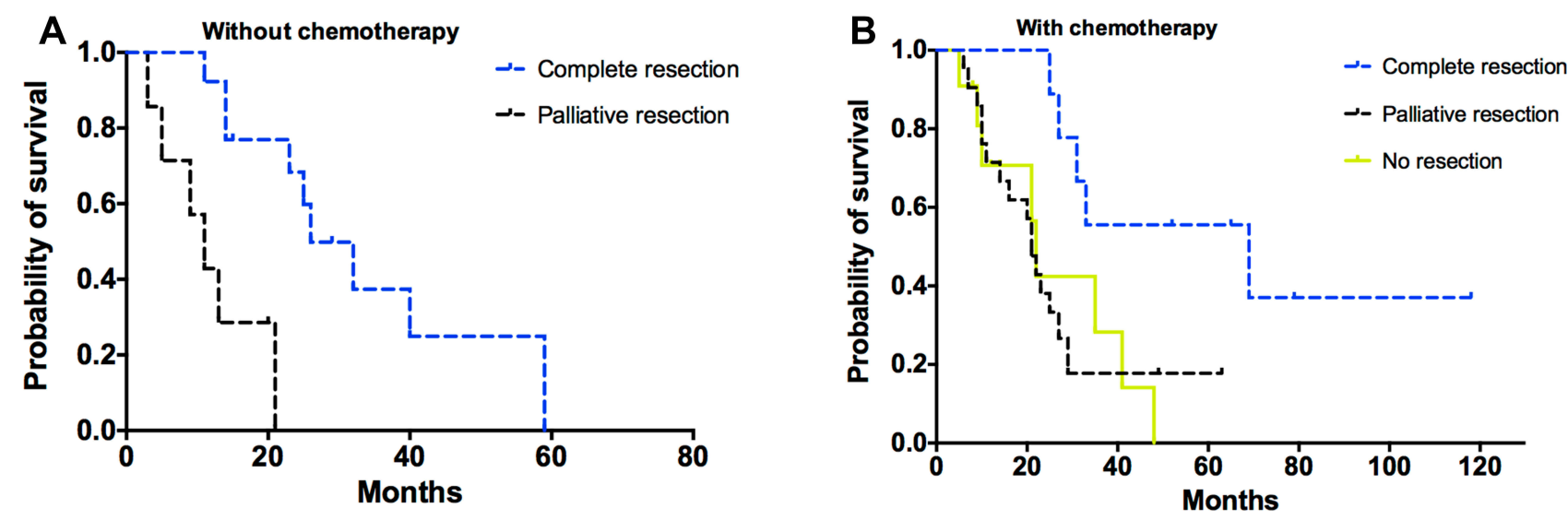

Figure 2 Disease-specific survival of patients receiving different surgical methods of ovarian metastases stratified by systemic chemotherapy. (A) Without chemotherapy, (B) receiving chemotherapy.

metastasectomy for survival. The retrospective study performed by Lee et $\mathrm{al}^{9}$ demonstrated that CRC patients with ovarian metastases received an oophorectomy before chemotherapy survived significantly longer than those without an oophorectomy (28.1 vs 21.2 months, $P=0.015$ ). Additionally, multivariate analysis indicated that no

Table 3 Multivariate Cox Regression Analysis of Ovarian Metastatic CRC Patients

\begin{tabular}{|c|c|c|c|}
\hline \multicolumn{2}{|l|}{ Variables } & \multirow{2}{*}{$\begin{array}{l}\text { HR }(95 \% \mathrm{CI}) \\
\text { I (Reference) } \\
0.490(0.094-2.560)\end{array}$} & \multirow{2}{*}{$\begin{array}{l}P \\
0.398\end{array}$} \\
\hline Age & $\begin{array}{l}>46.5 \text { years } \\
\leq 46.5 \text { years }\end{array}$ & & \\
\hline Menopausal status & $\begin{array}{l}\text { Postmenopausal } \\
\text { Premenopausal }\end{array}$ & $\begin{array}{l}\text { I (Reference) } \\
0.817(0.137-4.891)\end{array}$ & 0.825 \\
\hline CEA level & $\begin{array}{l}>U L N \\
\leq U L N\end{array}$ & $\begin{array}{l}\text { I (Reference) } \\
0.523(0.173-1.582)\end{array}$ & 0.251 \\
\hline Primary tumor location & $\begin{array}{l}\text { Rectum } \\
\text { Colon }\end{array}$ & $\begin{array}{l}\text { I (Reference) } \\
0.960(0.567-1.628)\end{array}$ & $0.88 I$ \\
\hline T stage of primary tumor* & $\begin{array}{l}\mathrm{T} 2+\mathrm{T} 3 \\
\mathrm{~T} 4\end{array}$ & $\begin{array}{l}\text { I (Reference) } \\
2.374(1.000-5.634)\end{array}$ & 0.050 \\
\hline $\mathrm{N}$ stage of primary tumor* & $\begin{array}{l}\text { Negative } \\
\text { Positive }\end{array}$ & $\begin{array}{l}\text { I (Reference) } \\
3.438 \text { (I.094-10.810) }\end{array}$ & 0.035 \\
\hline Primary tumor resection & $\begin{array}{l}\text { Yes } \\
\text { No }\end{array}$ & $\begin{array}{l}\text { I (Reference) } \\
6.436(1.770-23.399)\end{array}$ & 0.005 \\
\hline Histological type of primary tumor & $\begin{array}{l}\text { Adenocarcinoma } \\
\text { Mucinous adenocarcinoma }+ \text { signet-ring cell } \\
\text { carcinoma }\end{array}$ & $\begin{array}{l}\text { I (Reference) } \\
\text { I.522 (0.6I6-3.765) }\end{array}$ & 0.363 \\
\hline
\end{tabular}

(Continued) 
Table 3 (Continued).

\begin{tabular}{|c|c|c|c|}
\hline \multicolumn{2}{|l|}{ Variables } & \multirow{2}{*}{$\begin{array}{l}\text { HR }(95 \% \mathbf{C l}) \\
\text { I (Reference) } \\
0.272(0.107-0.693)\end{array}$} & \multirow{2}{*}{$\begin{array}{l}P \\
0.006\end{array}$} \\
\hline Differentiation grade of primary tumor & $\begin{array}{l}\text { Poorly differentiated } \\
\text { Well differentiated }\end{array}$ & & \\
\hline Synchronous metastasis & $\begin{array}{l}\text { No } \\
\text { Yes }\end{array}$ & $\begin{array}{l}\text { I (Reference) } \\
2.478(0.836-7.343)\end{array}$ & 0.102 \\
\hline Bilateral or unilateral metastasis & $\begin{array}{l}\text { Bilateral } \\
\text { Unilateral }\end{array}$ & $\begin{array}{l}\text { I (Reference) } \\
0.999(0.408-2.445)\end{array}$ & 0.998 \\
\hline $\begin{array}{l}\text { Combined with metastases outside } \\
\text { ovaries }\end{array}$ & $\begin{array}{l}\text { Yes } \\
\text { No }\end{array}$ & $\begin{array}{l}\text { I (Reference) } \\
0.890(0.190-4.157)\end{array}$ & 0.882 \\
\hline Ascites & $\begin{array}{l}\text { No } \\
\text { Yes }\end{array}$ & $\begin{array}{l}\text { I (Reference) } \\
\text { I.859 (0.803-4.303) }\end{array}$ & 0.147 \\
\hline Peritoneal metastasis & $\begin{array}{l}\text { No } \\
\text { Yes }\end{array}$ & $\begin{array}{l}\text { I (Reference) } \\
\text { I.I2I (0.435-2.889) }\end{array}$ & 0.813 \\
\hline Liver metastasis & $\begin{array}{l}\text { Yes } \\
\text { No }\end{array}$ & $\begin{array}{l}\text { I (Reference) } \\
0.560(0.214-1.463)\end{array}$ & 0.237 \\
\hline Lung metastasis & $\begin{array}{l}\text { Yes } \\
\text { No }\end{array}$ & $\begin{array}{l}\text { I (Reference) } \\
0.677(0.222-2.063)\end{array}$ & 0.493 \\
\hline The largest diameter of ovarian metastasis & $\begin{array}{l}>8.0 \mathrm{~cm} \\
\leq 8.0 \mathrm{~cm}\end{array}$ & $\begin{array}{l}\text { I (Reference) } \\
0.697(0.3|5-| .546)\end{array}$ & 0.375 \\
\hline Surgery of ovarian metastasis & $\begin{array}{l}\text { Complete resection } \\
\text { Palliative resection } \\
\text { No resection (chemotherapy only) }\end{array}$ & $\begin{array}{l}\text { I (Reference) } \\
\text { I7.09| (3.040-96.099) } \\
9.519(1.581-57.320)\end{array}$ & $\begin{array}{l}0.001 \\
0.014\end{array}$ \\
\hline Systemic chemotherapy & $\begin{array}{l}\text { Yes } \\
\text { No }\end{array}$ & $\begin{array}{l}\text { I (Reference) } \\
3.059(1.089-8.595)\end{array}$ & 0.034 \\
\hline
\end{tabular}

Notes: *In patients without primary tumor resection, the reported $\mathrm{T}$ and $\mathrm{N}$ stage were clinically evaluated based on imaging techniques; Bold text, significant $P$ values $(<0.05)$.

Abbreviations: CRC, colorectal cancer; mDSS, median disease-specific survival; CEA, carcinoembryonic antigen; ULN, upper limit of normal; Cl, confidence interval; HR, hazard ratio.

oophorectomy was an independent prognostic factor associated with poorer survival $(\mathrm{RR}=1.954, \quad 95 \%$ $\mathrm{CI}=1.220-3.130, P=0.005)$. This survival benefit of metastasectomy in ovarian metastatic CRC was confirmed by other retrospective studies too. ${ }^{13-18}$ However, a study published in
$2017^{19}$ suggested that patients treated with surgery of ovarian metastases and chemotherapy did not have better survival compared with those treated with chemotherapy alone (23 vs 28 months, $P=0.376$ ). Furthermore, Jiang et $\mathrm{al}^{20}$ analyzed the impact of residual disease on survival in metastatic ovarian 
cancer patients (mainly originated from gastric cancer and CRC) who underwent metastasectomy. They found that visible residual disease after metastasectomy independently predicted poorer survival $(P<0.01)$. Since the above studies were of small sizes and based on retrospective data, the role of metastasectomy in ovarian metastatic $\mathrm{CRC}$ still remains controversial. In our study, we found that complete resection of ovarian metastases could predict better survival $(\mathrm{DSS}=33.0$ months), while palliative and no resection of ovaries were factors of poorer prognosis $(P<0.05)$.

There were some limitations in this study, such as retrospective data, small sample size and single-center cohort. And due to small sample size, the differences of baseline situation (such as immunity, performance status) among the three groups may be overlooked. However, the large cohort and complete clinical information of our study confirmed the rarity of ovarian metastasis with an incidence of $3.1 \%$, indicated the survival benefit of complete resection of ovarian metastases and concluded several prognostic factors such as regional lymph nodes metastasis of primary tumor, primary tumor resection, differentiation grade, surgical methods of ovarian metastases and systemic chemotherapy. Our study suggested that limited ovarian metastases could be the candidates for surgery, which could help clinicians in making individualized treatment strategies. Well-designed prospective trial is warranted to verify this viewpoint.

\section{Abbreviations}

CRC, colorectal cancer; DSS, disease-specific survival; OS, overall survival; CK7, cytokeratin 7; CDX2, caudal-type homeobox transcription factor-2; CA125, carbohydrate antigen 125; PAX8, paired box gene 8; CEA, carcinoembryonic antigen; CT, computed tomography; CI, confidence interval; $\mathrm{HR}$, hazard ratio; ORR, objective response rate; DCR, disease control rate; RR, rate ratio; ULN, upper limit of normal; ECOG, Eastern Cooperative Oncology Group.

\section{Data Sharing Statement}

The data used to support the findings of this study are available from the corresponding author upon request.

\section{Ethical Approval and Informed Consent}

Written informed consent for the use of patient information in our study was obtained from all patients at the time of admission as a routine practice at West China Hospital, Sichuan University. And this study was approved by the West China Hospital, Sichuan University Ethic Committee for Clinical Investigation.

\section{Author Contributions}

All authors made substantial contributions to conception and design, acquisition of data, or analysis and interpretation of data; took part in drafting the article or revising it critically for important intellectual content; gave final approval of the version to be published; and agree to be accountable for all aspects of the work.

\section{Funding}

This work was supported by the National Key Development Plan for Precision Medicine Research (2017YFC0910004).

\section{Disclosure}

The authors declare no potential competing interests.

\section{References}

1. Hanna NN, Cohen AM. Ovarian neoplasms in patients with colorectal cancer: understanding the role of prophylactic oophorectomy. Clin Colorectal Cancer. 2004;3(4):215-222. doi:10.3816/CCC.2004.n.002

2. Mata JM, Inaraja L, Rams A, Andreu J, Donoso L, Marcuello G. CT findings in metastatic ovarian tumors from gastrointestinal tract neoplasms (Krukenberg tumors). Gastrointest Radiol. 1988;13(3): 242-246. doi:10.1007/BF01889071

3. Tunca JC, Starling JR, Hafez GR, Buchler DA. Colon carcinoma metastatic to the ovary. J Surg Oncol. 1983;23(4):269-272. doi:10. 1002/jso.2930230411

4. Herrera-Ornelas L, Natarajan N, Tsukada Y, et al. Adenocarcinoma of the colon masquerading as primary ovarian neoplasia. An analysis of ten cases. Dis Colon Rectum. 1983;26(6):377-380. doi:10.1007/ BF02553378

5. Mazur MT, Hsueh S, Gersell DJ. Metastases to the female genital tract. Analysis of 325 cases. Cancer. 1984;53(9):1978-1984. doi:10. 1002/1097-0142(19840501)53:9<1978::AID-CNCR2820530929>3.0. $\mathrm{CO} ; 2-1$

6. Dionigi A, Facco C, Tibiletti MG, Bernasconi B, Riva C, Capella C. Ovarian metastases from colorectal carcinoma. Clinicopathologic profile, immunophenotype, and karyotype analysis. Am J Clin Pathol. 2000;114 (1):111-122. doi:10.1309/G56H-97A2-JFMT-CD5N

7. Ates Ozdemir D, Usubutun A. PAX2, PAX8 and CDX2 expression in metastatic mucinous, primary ovarian mucinous and seromucinous tumors and review of the literature. Pathol Oncol Res. 2016;22 (3):593-599. doi:10.1007/s12253-016-0040-2

8. Goéré D, Daveau C, Elias D, et al. The differential response to chemotherapy of ovarian metastases from colorectal carcinoma. Eur J Surg Oncol. 2008;34(12):1335-1339. doi:10.1016/j.ejso.2008.03. 010

9. Lee SJ, Lee J, Lim HY, et al. Survival benefit from ovarian metastatectomy in colorectal cancer patients with ovarian metastasis: a retrospective analysis. Cancer Chemother Pharmacol. 2010;66 (2):229-235. doi:10.1007/s00280-009-1150-2 
10. Ribeiro Gomes J, Belotto M, D'Alpino Peixoto R. The role of surgery for unusual sites of metastases from colorectal cancer: a review of the literature. Eur J Surg Oncol. 2017;43(1):15-19. doi:10.1016/j.ejso.2016.05.019

11. Crobach S, Ruano D, van Eijk R, et al. Somatic mutation profiles in primary colorectal cancers and matching ovarian metastases: identification of driver and passenger mutations. J Pathol Clin Res. 2016;2 (3):166-174. doi:10.1002/cjp2.45

12. Ganesh K, Shah RH, Vakiani E, et al. Clinical and genetic determinants of ovarian metastases from colorectal cancer. Cancer. 2017;123 (7):1134-1143. doi:10.1002/cncr.30424

13. Garrett CR, George B, Viswanathan C, et al. Survival benefit associated with surgical oophorectomy in patients with colorectal cancer metastatic to the ovary. Clin Colorectal Cancer. 2012;11(3):191-194. doi:10.1016/j.clcc.2011.12.003

14. Sekine K, Hamaguchia T, Shojia H, et al. Retrospective analyses of systemic chemotherapy and cytoreductive surgery for patients with ovarian metastases from colorectal cancer: a single-center experience. Oncology. 2018;95(4):220-228. doi:10.1159/000489665

15. Huang PP, Weber TK, Mendonza C, Rodriguez-Bigas MA, Petrelli NJ. Long-term survival in patients with ovarian metastases from colorectal carcinoma. Ann Surg Oncol. 1998;5(8):695-698. doi:10.1007/BF02303479
16. McCormick CC, Giuntoli RL, Gardner GJ, et al. The role of cytoreduction surgery for colon cancer metastatic to the ovary. Gynecol Oncol. 2007;105(3):791-795. doi:10.1016/j.ygyno.2007.02.025

17. Fujiwara A, Noura S, Ohue M, et al. Significance of the resection of ovarian metastases from colorectal cancers. J Surg Oncol. 2010;102 (6):582-587. doi:10.1002/jso.21675

18. Rayson D, Bouttell E, Whiston F, Stitt L. Outcome after ovarian/ adnexal metastectomy in metastatic colorectal carcinoma. J Surg Oncol. 2000;75(3):186-192. doi:10.1002/1096-9098(200011) 75:3<186::AID-JSO6>3.0.CO;2-S

19. Kammar PS, Engineer R, Patil PS, Ostwal V, Shylasree TS, Saklani AP. Ovarian metastases of colorectal origin: treatment patterns and factors affecting outcomes. Indian J Surg Oncol. 2017;8 (4):519-526

20. Jiang $R$, Tang J, Cheng $X$, Zang RY. Surgical treatment for patients with different origins of Krukenberg tumors: outcomes and prognostic factors. Eur J Surg Oncol. 2009;35(1):92-97. doi: $10.1016 /$ j.ejso.2008.05.006

\section{Publish your work in this journal}

Cancer Management and Research is an international, peer-reviewed open access journal focusing on cancer research and the optimal use of preventative and integrated treatment interventions to achieve improved outcomes, enhanced survival and quality of life for the cancer patient.
The manuscript management system is completely online and includes a very quick and fair peer-review system, which is all easy to use Visit http://www.dovepress.com/testimonials.php to read real quotes from published authors. 